\title{
ANÁLISE DOS TEORES DE CHUMBO E NÍQUEL NA ESPÉCIE HYDROCOTYLE RANUNCULOIDES EM ÁREA ANTROPIZADA
}

Carolina Faccio Demarco - carol_demarco@ hotmail.com Universidade Federal de Pelotas

Thays França Afonso - thaysafonso@ hotmail.com

Universidade Federal de Pelotas

Mateus Torres Nazari - nazari.eas@gmail.com

Universidade Federal de Pelotas

Flávio Anastácio de Oliveira Camargo - fcamargo@ufrgs.br

Universidade Federal do Rio Grande do Sul

Maurízio Silveira Quadro - mausq@ hotmail.com

Universidade Federal de Pelotas

Robson Andreazza - robsonandreazza@yahoo.com.br

Universidade Federal de Pelotas 


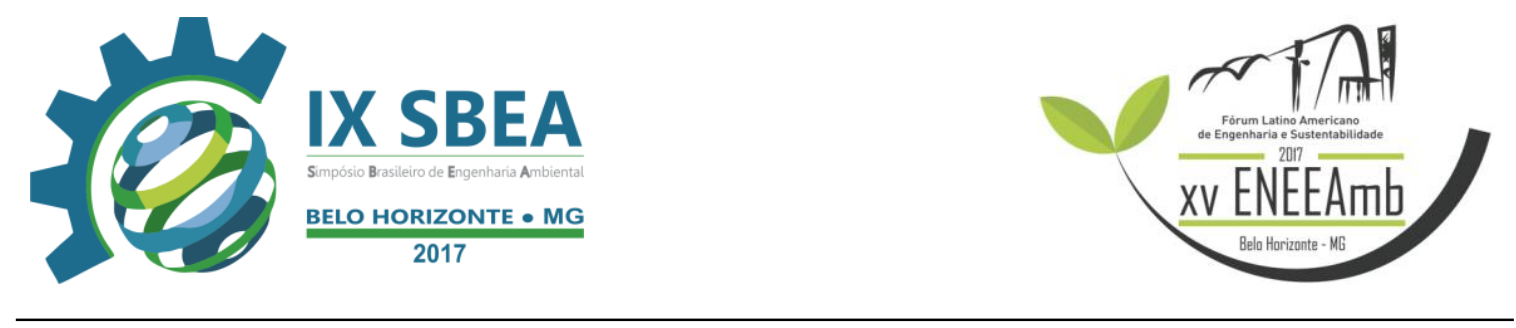

\section{RESUMO}

Devido a influência das ações antrópicas nos ecossistemas naturais e urbanos e a evidente necessidade de remediação desses locais afetados, este estudo objetivou analisar os teores de chumbo $(\mathrm{Pb})$ e níquel (Ni) na espécie de macrófita Hydrocotyle ranunculoides em área antropizada. O local selecionado para o estudo foi o arroio Santa Bárbara, no município de Pelotas/RS, área de ocorrência natural desta espécie. Foram feitas análises da concentração dos elementos $(\mathrm{Pb}$ e $\mathrm{Ni})$ na água e na planta, a partir da digestão em ácido nítrico e perclórico e quantificação por ICP- OES. Verificou-se que a água apresentou teores acima do permitido na legislação brasileira (Resolução CONAMA $357 / 2005)$ e a espécie analisada apresentou teores totais médios de $22,89 \mathrm{mg} \mathrm{kg}^{-1}$ de $\mathrm{Pb}$ e $8,56 \mathrm{mg} \mathrm{kg}^{-1}$ de Ni. Destaca-se a importância do papel fitorremediador que essa planta apresenta naturalmente e também a necessidade de análise de índices de fitorremediação para melhor qualificar os dados obtidos.

Palavras-chave: metal pesado; ambientes aquáticos contaminados; macrófitas.

\section{INTRODUÇÃO/OBJETIVO}

Devido ao crescimento populacional ao longo dos séculos e, consequentemente, a expansão das cidades, cada vez mais é notável a influência das ações antrópicas no distúrbio dos ecossistemas naturais e urbanos (SPINELLI et al., 2016). Corrêa et al. (2016) elaborando uma revisão histórica do entorno da bacia do manancial Santa Bárbara, no município de Pelotas/RS, e suas relações com a qualidade da água bruta, observou grande atividade antrópica na região responsável pela degradação e redução da qualidade da água nas regiões inferiores da bacia. Esta, é caracterizada por alta densidade populacional, baixa taxa de tratamento de esgoto, esgoto a céu aberto e acúmulo de resíduos nos logradouros.

A expansão urbana experimentada pelo município de Pelotas a partir da década de 1980 acabou por se refletir na bacia hidrográfica formadora do Reservatório Santa Bárbara, modificando características originais, o que possivelmente pode estar contribuindo, desde então, para a degradação da qualidade das águas dos arroios contribuintes e, consequentemente, do manancial em questão (KORB \& 
SUERTEGARAY, 2014). Os autores apontam que alguns outros fatores contribuem para um crescente comprometimento do tempo de vida útil e qualidade das águas, como por exemplo, a precariedade de planejamento de uso e ocupação do solo, pontual inexistência de um sistema de esgotamento sanitário e falta de programas de educação sanitária e ambiental que abranjam toda a população, além da multiplicidade de atividades na região, em um misto de urbana e rural. Simon (2007) também descreve que o crescente número de ocupações inadequadas às margens do arroio Santa Bárbara e o lançamento de efluentes domésticos e industriais sem tratamento contribuiu para que a região fosse impactada e possuísse vários problemas ambientais.

Outra alteração significativa na região foi a implantação do Aterro Controlado de Pelotas, desativado em 2012 pela Fundação Estadual de Proteção Ambiental - FEPAM, justamente pela proximidade com a Barragem Santa Bárbara, que é responsável pelo abastecimento de água de uma parte da cidade, bem como por estar localizado dentro do perímetro urbano na área central do município (ZANINI \& LESSA, 2013). Atualmente o Aterro Controlado passa por processos de manutenção obrigatório, conforme legislação específica. Estas ações englobam a vigilância 24 horas, estação de tratamento de lixiviados, manutenção de taludes, drenos de gás e de lixiviados (SANEP, 2017).

Em função da contaminação ambiental causada por atividades antrópicas, buscam-se estratégias de recuperação para essas áreas afetadas (VASCONCELLOS et al. 2012). Dependendo do tipo de contaminante presente no ambiente e das características locais, uma determinada técnica pode ser aplicada, tendo como principal objetivo fazer com que a área retorne o mais próximo possível às condições anteriores.

A possibilidade de se empregar macrófitas aquáticas como meio de reduzir a concentração de compostos orgânicos, metais pesados, fosfato e compostos nitrogenados já era discutida de maneira ampla anteriormente ao estudo limnológico de Esteves (1998), o qual descreveu o emprego de macrófitas aquáticas no controle de poluição e eutrofização artificial. A espécie Hydrocotyle ranunculoides é uma planta aquática perene da família Araliaceae e pertence à categoria de macrófitas enraizadas emergentes, que crescem em ambiente superficial lêntico ou lótico. Por ser resistente a teores de poluição elevados, torna-se um indicador útil em corpos de água com elevada concentração de matéria orgânica, nitratos e fosfatos (WANG et al., 1997, HUSSNER \& LOSH, 2007). 

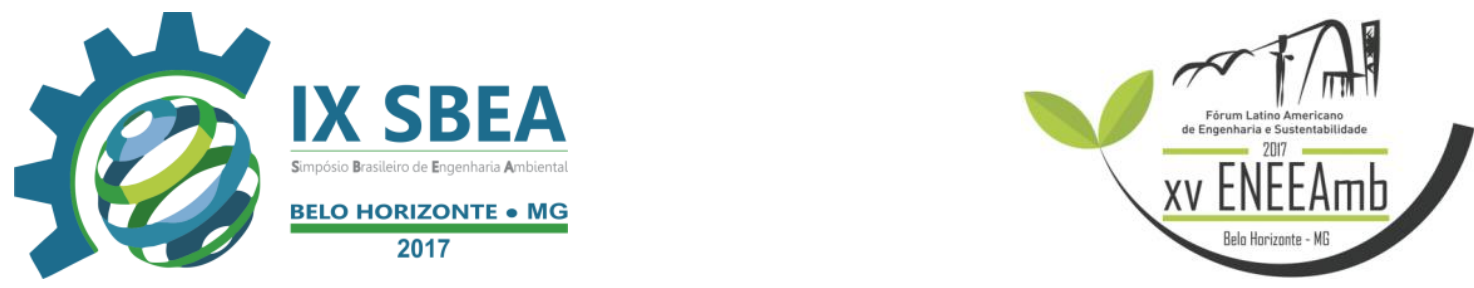

O objetivo geral deste trabalho foi analisar a remoção de chumbo e níquel que a espécie Hydrocotyle ranunculoides apresenta naturalmente no corpo hídrico selecionado. Também buscou-se verificar em qual parte da planta esses metais estão presentes em maiores concentrações. A principal relevância deste estudo, portanto, foi a detecção dos teores de chumbo e níquel na espécie de macrófita de ocorrência natural, visando posterior criação de uma alternativa para a remediação de ambientes aquáticos da região.

\section{METODOLOGIA}

A área onde a espécie de macrófita Hydrocotyle ranunculoides foi coletada está ilustrada na Figura 1 abaixo.

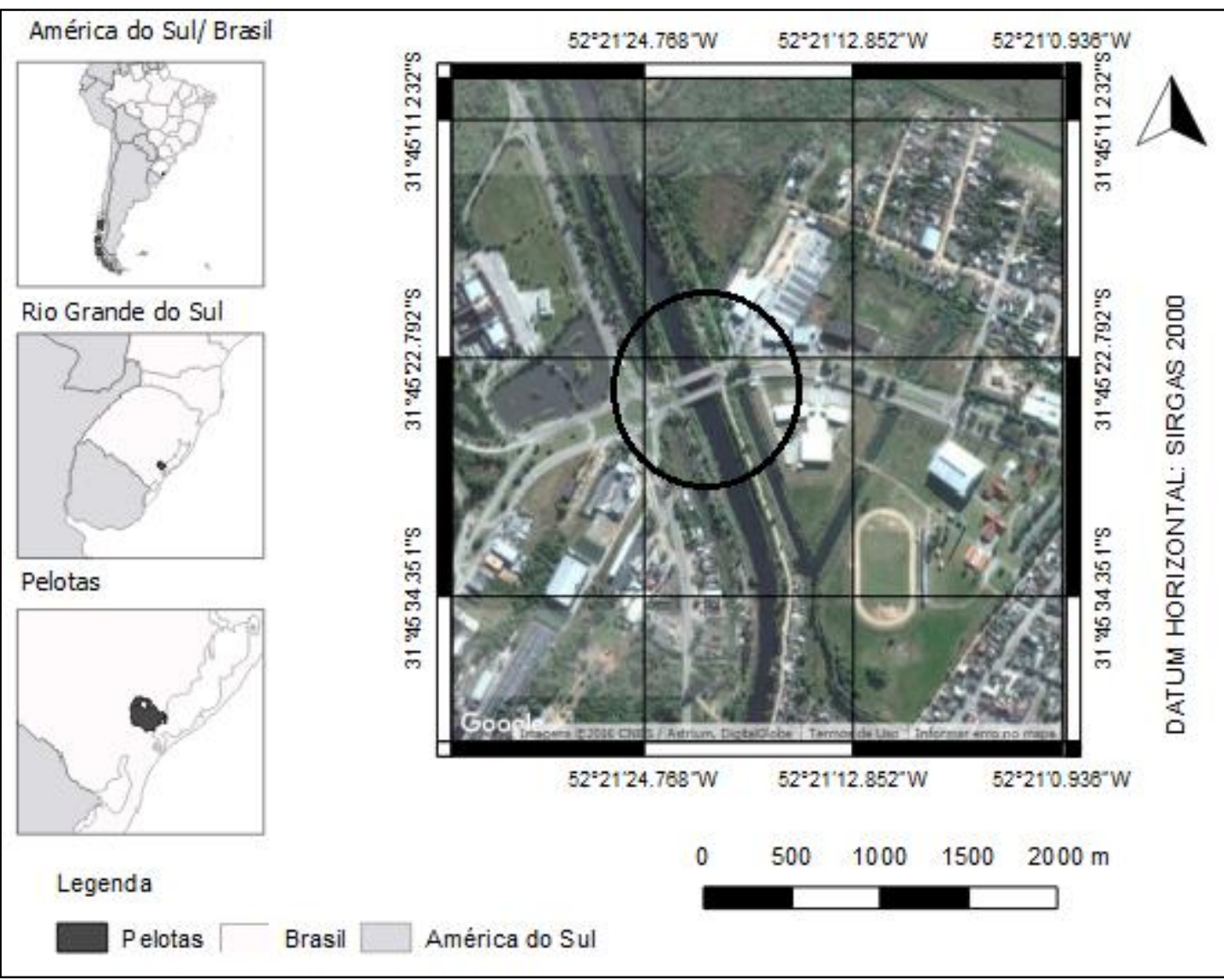

Figura 1 - Área selecionada do arroio Santa Bárbara para a coleta da espécie Hydrocotyle ranunculoides.

Para a análise da concentração de metais pesados nas plantas, a primeira etapa realizada foi a lavagem em água corrente e com água destilada, com o intuito de remover 
os sedimentos associados, seguida de secagem e digestão em ácido nítrico e perclórico de acordo com a metodologia de Tedesco et al. (1995). Esse processo de digestão tem como objetivo dissolver toda a amostra.

Após, foi feita a quantificação por plasma indutivamente acoplado espectrometria de emissão óptica (ICP-OES), no Laboratório de Solos da UFRGS. A análise na água foi realizada com a mesmo procedimento de digestão e posterior quantificação em ICP.

\section{RESULTADOS E DISCUSSÃO}

Os teores de chumbo e níquel detectados na água do arroio Santa Bárbara foram $0,015 \mathrm{mg} \mathrm{L}^{-1}$ e $0,15 \mathrm{mg} \mathrm{L}^{-1}$, respectivamente (Tabela 1 ). Os valores de referência da resolução CONAMA n 357/2005 para águas doces, padrões de Classe II, dos elementos são $0,01 \mathrm{mg} \mathrm{L}^{-1}$ e $0,025 \mathrm{mg} \mathrm{L}^{-1}$, para chumbo e níquel, respectivamente. A partir da comparação, verificou-se que os teores para os metais pesados analisados encontram-se acima do permitido na legislação brasileira. Este fato comprova a necessidade de remediar o ambiente aquático selecionado através da melhoria da qualidade da água e remoção desses elementos, visto que os metais pesados degradam-se muito lentamente no meio ambiente, persistindo durante décadas no solo e no fundo de rios, lagos e represas (JURAS, 2006).

Tabela 1 - Teores médios de Pb e Ni na água do arroio Santa Bárbara, Pelotas/RS.

\begin{tabular}{|c|c|c|}
\hline & Arroio Santa Bárbara & CONAMA Classe II \\
\hline & $-------------m^{-1}---15$ \\
\hline $\mathrm{Pb}$ & 0,015 & 0,01 \\
\hline $\mathrm{Ni}$ & 0,15 & 0,025 \\
\hline
\end{tabular}

As concentrações médias de chumbo na macrófita aquática Hydrocotyle ranunculoides foram de 7,14 $\mathrm{mg} \mathrm{kg}^{-1}$ na parte aérea, $15,75 \mathrm{mg} \mathrm{kg}^{-1}$ nas raízes e 22,89 mg $\mathrm{kg}^{-1}$ no total da planta (Tabela 2). Pode-se observar que a concentração foi mais elevada nas raízes da planta, confirmando a baixa mobilidade do elemento chumbo descrita por Kabata-Pendias \& Pendias (2001). 


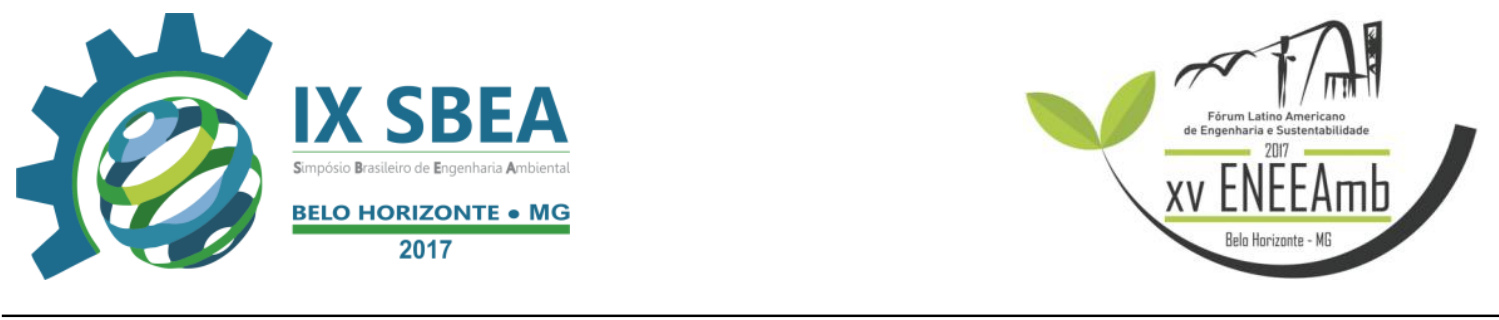

Jesus et al. (2015) ao avaliar a potencialidade de algumas espécies de macrófitas aquáticas como acumuladoras de metais pesados encontrou a maior concentração de chumbo de 17,33 $\mathrm{mg} \mathrm{kg}^{-1}$ ocorrendo naturalmente na espécie Acroceras zizanioides. Já Khatun et al. (2016) detectou valores de 48,3 $\mathrm{mg} \mathrm{kg}^{-1}$ para a espécie C. suculenta e 53,5 $\mathrm{mg} \mathrm{kg}{ }^{-1}$ para a espécie $S$. articulatus, ambas macrófitas aquáticas de ocorrência natural na localidade de East Kolkata Wetlands, Índia, caracterizada por receber grandes volumes de efluentes domésticos e industriais das áreas próximas.

Tabela 2 - Teores médios de $\mathrm{Pb}$ e Ni na espécie Hydrocotyle Ranunculoides (base seca, $\mathrm{mg} \mathrm{kg}^{-1}$ )

\begin{tabular}{|c|c|c|c|}
\hline & Parte aérea & Raízes & Total \\
\hline & $--------------\mathrm{mg} \mathrm{kg}^{-1}------$ \\
\hline $\mathrm{Pb}$ & 7,14 & 15,75 & 22,89 \\
\hline $\mathrm{Ni}$ & 2,16 & 6,40 & 8,56 \\
\hline
\end{tabular}

As concentrações médias de níquel para a espécie analisada foram $2,16 \mathrm{mg} \mathrm{kg}^{-1}$ na parte aérea, 6,40 $\mathrm{mg} \mathrm{kg}^{-1}$ nas raízes e $8,56 \mathrm{mg} \mathrm{kg}^{-1}$ no total da planta (Tabela 2). Assim como o elemento chumbo, o níquel foi detectado em maior concentração nas raízes da planta. Lojko et al. (2015) buscando avaliar a concentração de metais em espécies de macrófitas, detectou as seguintes concentrações de níquel: Sparganium erectum $6,81 \mathrm{mg}$ $\mathrm{kg}^{-1}$, Glyceria máxima 4,41 mg kg-1, Phalaris arundinacea 4,36 mg kg-1, Phragmites australis $1,66 \mathrm{mg} \mathrm{kg}^{-1}$ e concluiu que para este elemento, todas as espécies possuíam valores acima do que é comumente encontrado em plantas aquáticas.

A concentração mais elevada dos metais chumbo e níquel na parte das raízes poderia ser justificado pelo fato de a espécie em questão apresentar um sistema fibroso em suas raízes, com uma grande área de contato, a qual permite acumular grandes concentrações de metais (MEJARE \& BÜLOW, 2001; LU et al., 2004; OLIVARES et al., 2007). Desta forma elas podem atuar como uma barreira inicial absorvendo ou retendo os metais não essenciais ou tóxicos 


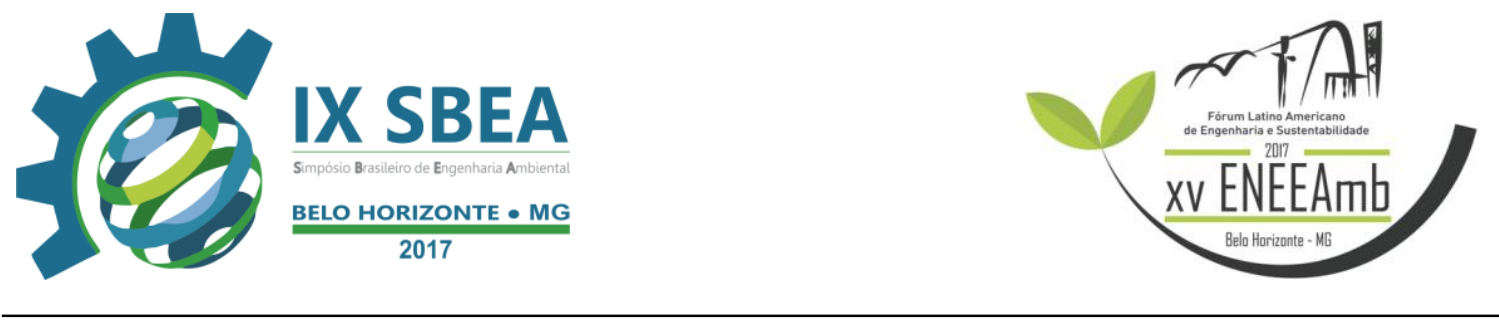

\section{CONCLUSÕES/RECOMENDAÇÕES}

Conclui-se que a espécie Hydrocotyle ranunculoides apresentou concentração consideravelmente elevada dos metais chumbo e níquel, evidenciando o seu papel natural de fitorremediação no ambiente aquático. Destaca-se a relevância de futuramente aplicar as informações obtidas neste estudo para a criação de propostas de remediação dos corpos hídricos da região. Recomenda-se, contudo, a utilização de cálculos de índices de fitorremediação para melhor qualificar os dados obtidos, em conjunto com pesquisa mais aprofundada acerca da espécie.

\section{REFERÊNCIAS BIBLIOGRÁFICAS}

BRASIL, Resolução CONAMA 357, de 17 de março de 2005. Ministério do Meio Ambiente. Classificação de águas, doces, salobras e salinas do Território Nacional.

CORRÊA, H, K. Revisão histórica do entorno da bacia do manancial Santa Bárbara Pelotas /RS e suas relações com a qualidade da água bruta dos anos 2013 a 2015. In: $10^{\circ}$ Simpósio Internacional de Qualidade Ambiental, Porto Alegre, 2016. Anais $10^{\circ}$ Simpósio Internacional de Qualidade Ambiental, Porto Alegre, 2016.

ESTEVES, Francisco de Assis. Fundamentos de Limnologia. 2 ed. Rio de Janeiro: Interciência. 1998, 226p.

JESUS, T. B.; SOUZA, S. S., SANTOS, L. T. S. O.; AGUIAR, W. M. Avaliação da Potencialidade de Utilização de Espécies de Macrófitas como Acumuladoras de Metais Pesados. Revista Virtual de Química, v. 7. n. 4, p. 1102-1118, 2015

JURAS, Ilidia. Consequências do uso do chumbo na pesca. Biblioteca digital da câmara de deputados, 2016. Disponível em <http://bd.camara.gov.br>. Acesso em 30 de maio de 2017.

KABATA-PENDIAS, Alina.; PENDIAS, Henryk. Trace elements in soils and plants. 3 ed. Boca Raton, CRC Press, 2001. 413p.

KHATUN, A.; PAL, S.; MUKHERJEE, A. K.; SAMANTA, P.; MONDAL, S.; KOLE, D.; CHANDRA, P.; GHOSH, A. R. Evaluation of metal contamination and phytoremediation potential of aquatic macrophytes of East Kolkata Wetlands, India. Environmental Health and Toxicology. v. 31, p. 1- 7, 2016.

KORB, C, C.; SUERTEGARAY, D. M. A. Identificação de depósitos tecnogênicos em um reservatório de abastecimento de água da cidade de Pelotas ( RS ). Quaternary and Environmental Geosciences, v. 5, n. 1., p. 41-54, 2014. 


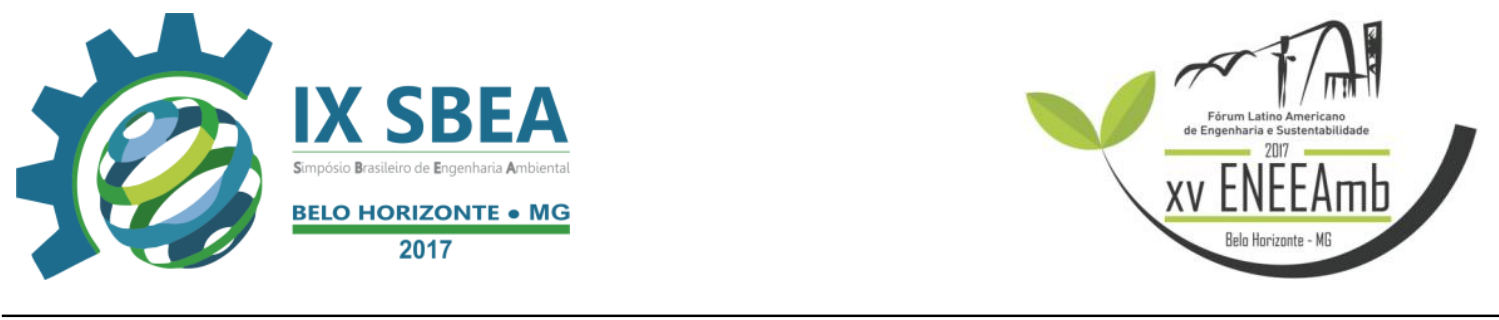

LOJKO, R.; POLECHOŃSKA, L.; KLINK, A. KOSIBA, P. Trace metal concentrations and their transfer from sediment to leaves of four common aquatic macrophytes. Environ Sci Pollut Res, p.1-9, 2015.

LU X.; KRUATRACHUE, M.; POKETHITIYOOK, P.; HOMYOK, K. Removal of cadmium and zinc by water hyacinth, Eichhornia crassipes. ScienceAsia, v. 30, p. 93103, 2004.

MEJARE, M; BÜLOW L. Metal-binding proteins and peptides in bioremediation and phytoremediation of heavy metals. Trends Biotechnology. v. 19, n. 2, p. 67-73, 2001.

OLIVARES-RIEUMONT, S.; LIMA, L.; DE LA ROSA, D.; GRAHAM, D. W.; COLUMBIE, I.; SANTANA, J. L.; SANCHEZ, M. J. Water Hyacinths (Eichhornia crassipes) as Indicators of Heavy Metal Impact of a Large Landfill on the Almendares River near Havana, Cuba. Bull Environ Contam Toxicol. v. 79, p. 583-587, 2007.

SANEP. Serviço Autônomo de Saneamento de Pelotas. Destinação final de Resíduos Sólidos. Disponível em < http://www.pelotas.rs.gov.br/sanep/> acesso em 21 de maio de 2017.

SIMON, A. L. H.; GONÇALVES, A. M. B. A.; HILSINGER, R.; NOAL, R. E. Impactos Ambientais e estado de degradação ambiental do Canal do Santa Bárbara, Município de Pelotas, R.S. In: Simpósio Brasileiro de Geografia Física Aplicada, 10, 11 p., 2007. Anais eletrônicos. Disponível em <http://www.cibergeo.org/XSBGFA/eixo3/3.3/202/202.htm>. Acesso em: 28 de janeiro de 2016.

SPINELLI, M. V. P.; CARVALHO, R. M. C. M. O. SILVA, H. P.; BRANDÃO, S. S. F. ; FRUTUOSO, M. N. M. A. Estudo sustentável da capacidade de carga antrópica e a sua influência no ponto de equilíbrio da resiliência ambiental. Revista Brasileira de Geografia Física, v. 9, n. 1, p. 185-199, 2016.

TEDESCO, M. J; GIANELLO, C.; BISSANI. C. A.; BOHNEN, H.; VOLKWEISS, S. J. Análises de solo, plantas e outros materiais. Porto Alegre: Universidade Federal do Rio Grande do Sul, Faculdade de Agronomia 1995, 174p.

VASCONCELLOS M. C.; PAGLIUSO, D.; SOTOMAIOR, V. S. Fitorremediação: Uma proposta de descontaminação do solo. Estud. Biol., Ambiente Divers. v. 34, n.83, p. 261-267, 2012.

ZANINI, S. R. D.; LESSA, V. N. Gestão de Resíduos Sólidos: o Resíduo Urbano e sua Alocação no Município de Pelotas. Revista Eletrônica Academicus - ReA, v. 1, n. 1, p., 25- 42, 2013. 